\title{
hnRNP A1 regulates UV-induced NF- $\kappa$ B signalling through destabilization of cIAP1 mRNA
}

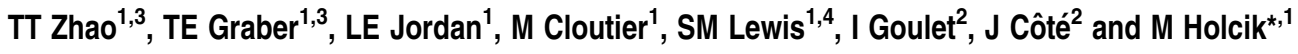

cIAP1 is an important member of the inhibitor of apoptosis family of proteins and is involved in the regulation of the NF- $\kappa \mathrm{B}-$ signalling pathway downstream of the TNF receptor. We report here that UV irradiation leads to downregulation of cIAP1 expression because of enhanced cIAP1 mRNA destabilization. An AU-rich element located within the $3^{\prime}$ untranslated region of cIAP1 mRNA is sufficient to mediate cIAP1 mRNA instability. Furthermore, we have identified hnRNP A1 as a cIAP1 $3^{\prime}$ UTR-binding protein. hnRNP A1 is a primarily nuclear protein, but accumulates in the cytoplasm after exposure of cells to UV irradiation. Indeed, we find that hnRNP A1 enhances the destabilization of cIAP1 mRNA during UV irradiation. Moreover, siRNAmediated knockdown of hnRNP A1 restores clAP1 levels and prevents UV irradiation-induced activation of the NF- $\kappa$ B signal transduction pathway, suggesting that hnRNP A1 is an essential post-transcriptional modulator of clAP1 expression, and thus cIAP1 activity.

Cell Death and Differentiation (2009) 16, 244-252; doi:10.1038/cdd.2008.146; published online 10 October 2008

The inhibitor of apoptosis (IAP) family of proteins are key regulators of programmed cell death. ${ }^{1}$ The IAP family comprises eight distinct members that participate in diverse cellular processes including cell cycle, signal transduction, ubiquitylation, and caspase inhibition. ${ }^{2}$ Although it was initially believed that all IAPs are capable of inhibiting distinct caspases, the recent data suggest that only XIAP is a bona fide caspase inhibitor. ${ }^{3}$ CIAP1 and CIAP2 were identified through an interaction with the TNF-receptor complex proteins TRAF1 and TRAF2, which regulate NF- $\kappa$ B signalling through the TNF receptor. ${ }^{4}$ The C-terminal RING finger domain of clAP1 possesses an ubiquitin E3 ligase activity and may sensitize cells to apoptosis by direct ubiquitylation and removal of TRAF2 following activation of the TNF receptor, resulting in the inhibition of NF- $\kappa \mathrm{B}$ pathways. ${ }^{5}$ Indeed, CIAP1 degradation induced by Smac mimetics leads to activation of both the canonical and non-canonical NF- $\kappa$ B pathways, strengthening the importance of IAPs in the regulation of NF- $\kappa$ B signalling. ${ }^{6-8}$

Although cIAP1 and CIAP2 perform similar functions within the cell, their expression is regulated differently. The expression of cIAP2 is controlled primarily at the level of transcription in an NF- $\kappa$ B-dependent manner. ${ }^{9}$ Also, the protein turnover of CIAP2 is regulated by the ubiquitin ligase activity of clAP1 $1{ }^{10} \mathrm{In}$ contrast, clAP1 levels are controlled at the level of protein synthesis. The $5^{\prime}$ untranslated region (UTR) of clAP1 contains an upstream open reading frame that reduces the basal translation of ClAP1. ${ }^{11}$ The $5^{\prime}$ UTR of ClAP1 also harbours an internal ribosome entry site (IRES) element that mediates translational induction of clAP1 in response to stress. ${ }^{12,13}$ This complex regulatory network reflects the distinct spatial and temporal requirement for CIAP1 and clAP2 proteins in response to various physiological conditions.

Here, we describe an additional regulatory mechanism that governs the expression of ClAP1. We find that following UV irradiation the levels of cIAP1 decrease dramatically. This reduction of cIAP1 protein is achieved by destabilization of clAP1 mRNA. We have identified an AU-rich (ARE) sequence in the $3^{\prime}$ UTR of ClAP1 that is sufficient and necessary to confer instability on a reporter mRNA. Furthermore, we find that the heterogeneous ribonucleoprotein A1 (hnRNP A1) interacts with the cIAP1 $3^{\prime}$ UTR and regulates CIAP1 mRNA stability. Importantly, UV irradiation mediates accumulation of hnRNP A1 in the cytoplasm and subsequent destabilization of clAP1 mRNA, which results in reduced clAP1 protein levels and consequently increased NF- $\kappa$ B signalling.

\section{Results}

UV irradiation destabilizes cIAP1 mRNA and reduces cIAP1 protein levels. UV irradiation (UVR) causes cells to mount a response to deal with the potentially harmful effects of UV-induced damage. We have earlier reported that UVR

\footnotetext{
${ }^{1}$ Apoptosis Research Centre, Children's Hospital of Eastern Ontario, 401 Smyth Road, Ottawa, Canada K1H 8L1 and 2Department of Cellular and Molecular Medicine and Center for Neuromuscular Research, Faculty of Medicine, University of Ottawa, 451 Smyth Road, Ottawa, Canada K1H 8M5

*Corresponding author: M Holcik, Apoptosis Research Centre, Children's Hospital of Eastern Ontario, 401 Smyth Road, Ottawa, ON Canada, K1H $8 \mathrm{~L} 1$.

Tel: + 613738 3207; Fax: + 613738 4833; E-mail: martin@arc.cheo.ca

${ }^{3}$ These authors contributed equally to this work

${ }^{4}$ Present address: Atlantic Cancer Research Institute, Hôtel-Dieu Pavilion, 35 Providence Street, Moncton, New Brunswick, Canada, E1C 8X3

Keywords: mRNA stability; ARE; RNA binding protein; inhibitor of apoptosis; UV irradiation

Abbreviations: ARE, AU-rich element; CAT, chloramphenicol acetyl transferase; hnRNP A1, heterogeneous ribonucleoprotein A1; IAP, inhibitor of apoptosis; IRES, internal ribosome entry site; NEO, neomycin phosphotransferase; NF- $\kappa B$, nuclear factor kappa B; RING, really interesting new gene; TNF $\alpha$, tumour necrosis factor $\alpha$; UTR, untranslated region; UVR, UV irradiation

Received 28.4.08; revised 18.7.08; accepted 27.8.08; Edited by J Silke; published online 10.10.08
} 
results in an inhibition of global protein synthesis, whereas simultaneously enhancing translation of the proapoptotic protein Apaf-1 through an IRES-dependent mode of translation. ${ }^{14}$ In the course of these experiments we observed that the levels of the anti-apoptotic gene clAP1 were significantly reduced following UVR (Figure 1a). We wished to determine if this reduction in clAP1 levels is because of changes in protein or mRNA stability. UV-irradiated cells were pulsechased with ${ }^{35} \mathrm{~S}$ Met/Cys and clAP1 was immunoprecipitated over the course of $24 \mathrm{~h}$. We observed that UVR did not alter the stability of clAP1 protein (Figure 1b). We next examined the steady-state levels of clAP1 mRNA following UVR. When compared with the levels in non-irradiated HEK293 cells, the steady-state levels of endogenous clAP1 mRNA decreased significantly in UV-irradiated cells (Figure 1c). This suggests that the decrease in clAP1 protein levels following UVR could be because of changes in the stability of cIAP1 mRNA. We examined the stability of endogenous clAP1 mRNA following UVR by quantitative RT-PCR (Figure 1d). Indeed, this experiment revealed that the half-life of clAP1 mRNA $\left(t_{1 / 2}=5.9 \mathrm{~h}\right)$ is significantly reduced by UVR $\left(t_{1 / 2}=3.3 \mathrm{~h}\right)$. These results demonstrate that UVR causes a significant decrease in clAP1 protein levels by destabilizing clAP1 mRNA.

The $3^{\prime}$ UTR of clAP1 contains an AU-rich element that destabilizes cIAP1 mRNA following UVR. The stability of an mRNA is usually determined by sequence elements located within its $3^{\prime} U T R$. We therefore investigated whether the $3^{\prime} U T R$ of clAP1 can confer instability on a reporter mRNA. In the reporter vector pMC the expression of chloramphenicol acetyl transferase (CAT) reporter mRNA is driven by a CMV promoter and is post-transcriptionally regulated by the sequence elements inserted downstream of the CAT gene. This plasmid also expresses the neomycin phosphotransferase gene (NEO) from an independent promoter (SV40), which serves as an internal control. Insertion of the full-length $3^{\prime} \mathrm{UTR}$ of TNF $\alpha$, known to confer mRNA instability, downstream of the CAT reporter gene resulted in an approximately 10-fold reduction in CAT mRNA levels (Figure 2a). Insertion of the full-length cIAP1 $3^{\prime} U T R$ resulted in an approximately 3 -fold reduction in CAT mRNA levels. The levels of clAP1 $3^{\prime} U T R-C A T$ mRNA decreased even further following UVR, confirming that the $3^{\prime}$ UTR of clAP1 harbours the necessary elements to destabilize reporter mRNA. To further delineate the sequences that are required for cIAP1 mRNA instability we constructed a series of deletion mutants of the clAP1 $3^{\prime}$ UTR (Figure 2b). We observed that a 120 nucleotide fragment (120-240) is necessary and sufficient to confer instability on CAT mRNA (Figure 2c).

Inspection of the (120-240) fragment of the clAP1 $3^{\prime}$ UTR revealed that it contains four ARE (Figure 2b). To determine if these sequences are involved in destabilization of clAP1 a

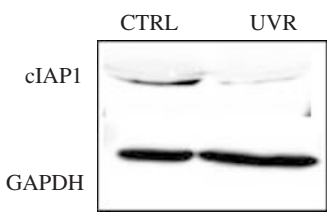

C

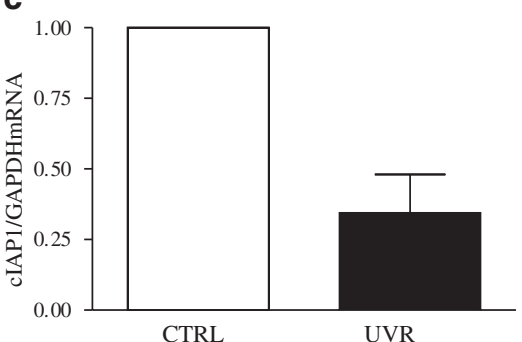

b methionine UV "S-methionine
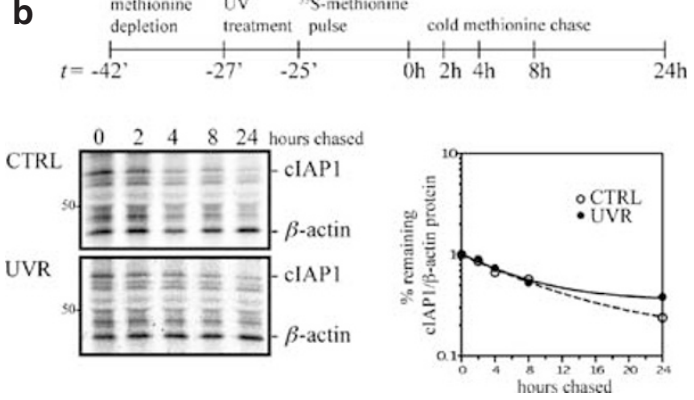

d

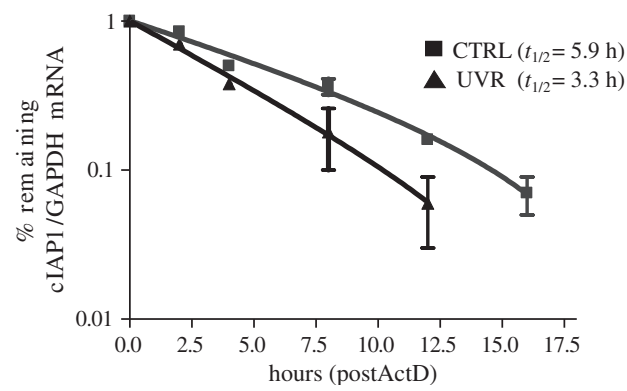

Figure 1 UV irradiation destabilizes cIAP1 mRNA. (a) UV irradiation reduces clAP1 protein levels. 293 cells were treated with UV irradiation (UVR (150 mW/ $\left.\left.\mathrm{cm}^{2}\right)\right)$ or not (CTRL) and the expression of cIAP1 protein was determined $24 \mathrm{~h}$ later by western blot. (b) UV irradiation does not affect clAP1 protein stability. Cells were pulsed with ${ }^{35} \mathrm{~S}-\mathrm{Met} /$ Cys for $25 \mathrm{~min}$ following UV irradiation and chased in the presence of cold Met/Cys for an additional $24 \mathrm{~h}$. cIAP1 and $\beta$-actin were immunoprecipitated using specific antibodies at indicated time points and resolved on SDS-PAGE (left). The levels of remaining cIAP1 are shown relative to $\beta$-actin, and the clAP1/ $\beta$-actin ratio at the beginning of cold Met chase $(0 \mathrm{~h}$ ) was set as 1 for both control and UVR samples (right). (c) UV irradiation reduces steady-state levels of cIAP1 mRNA. 293 cells were treated with UV irradiation as in (a) and $5 \mathrm{~h}$ later the total RNA was extracted. The levels of cIAP1 and GAPDH mRNA were determined by quantitative RT-PCR analysis as described in the Material and methods section; values are expressed as cIAP1 relative to GAPDH $\left(2^{-\left[C_{(}(\mathrm{ClAP} 1)-G_{1}(\mathrm{GAPDH})\right]}\right)$, and the ratio for non-irradiated cells was set as 1. Mean \pm S.D. of three experiments. (d) UV irradiation destabilizes cIAP1 mRNA. The cells were treated as in (c) and Actinomycin D (ActD, $10 \mu \mathrm{g} / \mu$ l) was added immediately following UV exposure. Total RNA was extracted from parallel samples at $0,4,8,12$, and $16 \mathrm{~h}$ time points and the levels of clAP1 and GAPDH mRNA were determined as in (c). Values are expressed as clAP1 relative to GADPH $\left(2^{-\left[\mathcal{C}_{t}(\mathrm{CIAP} 1)-\mathcal{G}_{\mathrm{t}}(\mathrm{GAPDH})\right]}\right)$ normalized to the $0 \mathrm{~h}$ time point, which was set as 1 . The mean \pm S.D. of three independent experiments is shown 


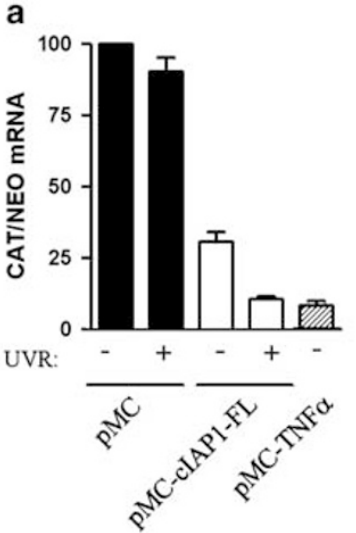

C

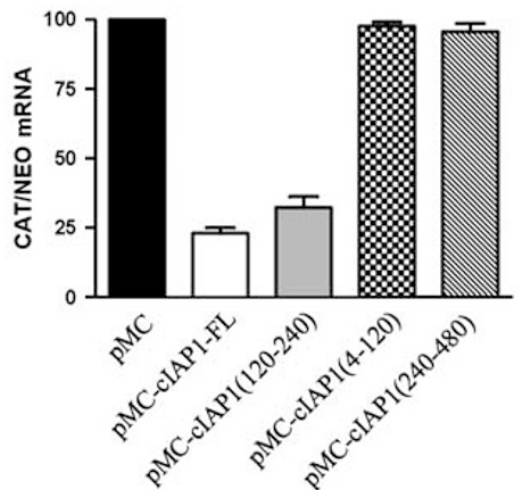

b

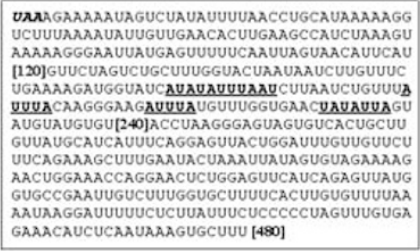

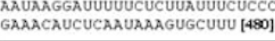

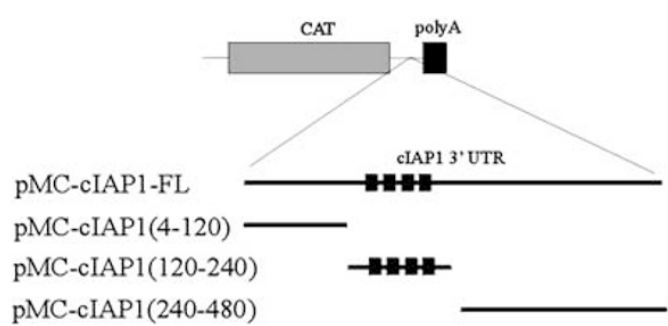

d

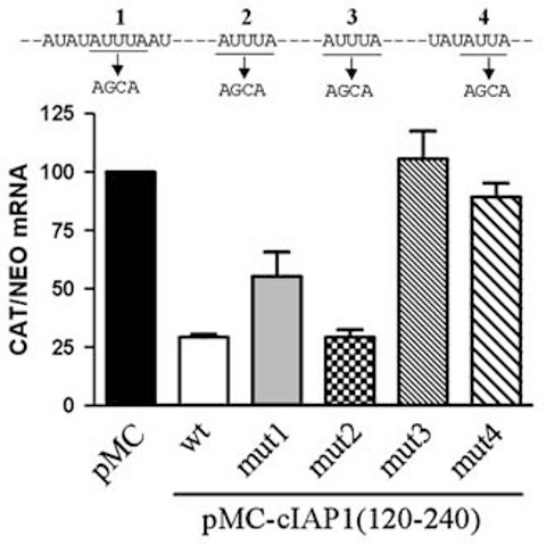

Figure 2 A fragment of cIAP1 $3^{\prime}$ UTR that contains AREs is sufficient to destabilize a heterologous reporter mRNA. (a) $3^{\prime}$ UTR of clAP1 is sufficient to destabilize reporter mRNA. 293 cells were transiently transfected with the indicated plasmids and the total RNA was extracted $24 \mathrm{~h}$ later. The levels of CAT and NEO mRNA were determined by quantitative RT-PCR analysis. Values are expressed as CAT relative to NEO $\left(2^{-\left[C_{t}(C A T)-C_{t}(\mathrm{NEO}]\right.}\right)$ and the ratio in non-irradiated cells transfected with the control plasmid pMC was set as 100 . The mean \pm S.D. of three independent experiments is shown. (b) The complete sequence of the $3^{\prime} U T R$ of clAP1. The stop codon is shown in bold italics. The putative AU-rich elements (AREs) are made bold and underlined. The numbers in square brackets denote nucleotide position relative to the stop codon. A schematic diagram of reporter plasmids is shown below; AREs are indicated as black rectangles. (c) A $120 \mathrm{nt}$ fragment harbouring the cIAP1 AREs is sufficient to destabilize the mRNA. 293 cells were transfected with the indicated plasmids and total RNA was extracted as in (a). The levels of CAT and NEO mRNA were determined $24 \mathrm{~h}$ later by quantitative RTPCR analysis as in (a). The mean \pm S.D. of three independent experiments is shown. (d) clAP1 AREs no. 3 and no. 4 are necessary to confer mRNA instability. Mutations of individual ARE modules (shown above the graph) were introduced into the reporter plasmid pMC-clAP1 (120-240) by site-directed mutagenesis. Indicated reporter plasmids were then transiently transfected into 293 cells and the levels of CAT and NEO mRNA were determined $24 \mathrm{~h}$ later by quantitative RT-PCR analysis as in (a). The mean \pm S.D. of three independent experiments is shown

mRNA, the individual ARE segments were mutated and tested for their ability to destabilize CAT mRNA (Figure 2d). We found that although mutation of the ARE no. 2 had no effect on the stability of the reporter mRNA (when compared with the wild-type sequence), mutations in either ARE no. 3 or ARE no. 4 completely abolished mRNA instability conferred by the cIAP1 $3^{\prime}$ UTR. In contrast, mutation of the ARE no. 1 produced an intermediate phenotype with partial restoration of CAT mRNA stability.

The results presented above confirm that the $3^{\prime} U T R$ of clAP1 contains an mRNA instability element, and that AU-rich elements no. 3 and no. 4 within the $3^{\prime}$ UTR are the major elements contributing to destabilization of the mRNA.
hnRNP A1 binds the cIAP1 3'UTR ARE. To identify proteins that interact with the clAP1 $3^{\prime}$ UTR we used an RNA-affinity chromatography approach ${ }^{15}$ followed by western blot with antibodies against candidate RNA-binding proteins, which identified hnRNP A1 as a clAP1 3'UTRinteracting protein (Figure $3 a$ ). In contrast, TIA-1, TIAR, and hnRNP C1/C2 (known RNA-binding proteins) were not detected in the protein eluate from the cIAP1 $3^{\prime} U T R$ RNAaffinity matrix, demonstrating the specificity of the hnRNP A1 interaction with the cIAP1 $3^{\prime}$ UTR in vitro.

We next investigated if hnRNP A1 binds directly to clAP1 $3^{\prime}$ UTR RNA, and performed a UV-crosslinking experiment using a radiolabeled cIAP1 3 'UTR RNA probe and purified recombinant GST-hnRNP A1 protein. In addition, we used the 
a

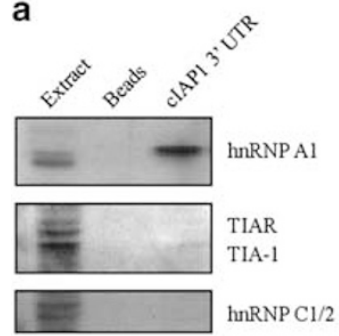

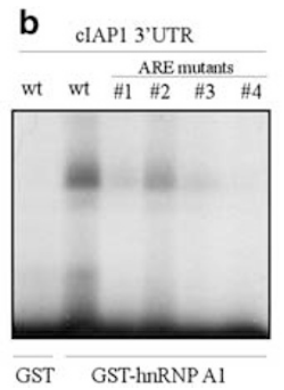

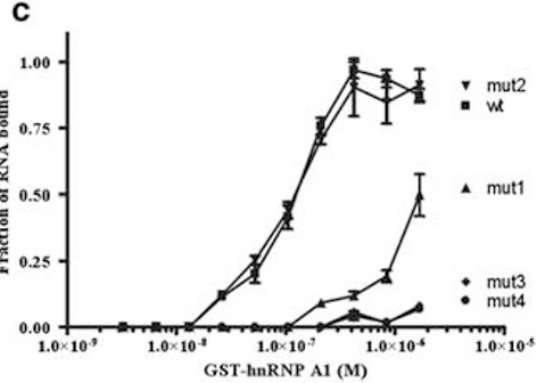

Figure 3 hnRNP A1 binds directly to the ARE-containing sequence of the cIAP1 $3^{\prime} U T R$. (a) RNA-affinity chromatography isolation of cIAP1 3'UTR-binding proteins. Precleared protein extracts from 293 cells were incubated with either agarose beads coated with cIAP1 3'UTR 120-240 RNA or agarose beads alone. After protein binding, beads were washed extensively, pelleted, and proteins were eluted by boiling. Following separation by SDS-PAGE the proteins were detected by western blot using the indicated antibodies. (b) Recombinant hnRNP A1 binds directly to the cIAP1 3 'UTR. GST (lane 1) or GST-hnRNP A1 (lanes 2, 3) were incubated with [ ${ }^{32}$ P]-labeled wild type (wt) or mutated cIAP1 $3^{\prime}$ UTR RNA probes, UV-crosslinked, and then separated by SDS-PAGE and visualized by autoradiography. (c) hnRNP A1 binding curves for cIAP1 $3^{\prime} U T R$ wild type and ARE mutant RNAs. Nitrocellulose filter-binding assays were performed and analyzed as described in Materials and Methods. Filter-bound RNA is plotted as a function of protein concentration. The data presented represent the mean \pm S.D. of three independent experiments

cIAP1 $3^{\prime}$ UTR ARE mutants, described in a previous experiment (Figure 2d). We find that cIAP1 $3^{\prime} U T R$ RNA is crosslinked to GST-hnRNP A1 (Figure 3b), indicating that hnRNP A1 does indeed bind directly to clAP1 RNA. Importantly, GSThnRNP A1 failed to bind to the ARE mutants no. 1 , no. 3 and no. 4, whereas it bound ARE mutant no. 2, implicating these ARE sites as hnRNP A1-binding sites within the clAP1 3'UTR.

We further assessed the interaction between hnRNP A1 and the CIAP1 $3^{\prime}$ UTR by measuring the apparent equilibrium dissociation constant $(K d)$ of the recombinant GST-hnRNP A1 protein with both the wild-type cIAP1 3'UTR and ARE-mutant sequences by a nitrocellulose filter-binding assay. We find that the $K d$ for the interaction between GST-hnRNP A1 and clAP1 $3^{\prime}$ UTR RNA is $122 \mathrm{nM}$ (Figure 3c). Importantly, this $K d$ value is similar to the $K d$ values reported earlier for the interactions between hnRNP A1 and other target mRNAs, ${ }^{16-18}$ suggesting a bona fide and specific interaction. An almost identical binding curve was observed for the ARE no. 2 mutant RNA (mut2), whereas the $K d$ for an interaction between GST-hnRNP A1 and ARE no. 1, no. 3, and no. 4 mutant RNAs (mut1, mut3, and mut4) is greater than $600 \mathrm{nM}$ (we could not determine the actual value as we were unable to saturate binding). Interestingly, the binding affinity of GST-hnRNP A1 for the various cIAP1 3'UTR ARE mutants correlates with the ability of these mutants to destabilize CAT reporter mRNA (compare Figure $3 c$ and Figure $2 d$ ), suggesting that hnRNP $A 1$ is a major factor in the instability of clAP1 mRNA.

hnRNP A1 regulates levels of clAP1 in response to UVR. hnRNP A1 accumulates in the cytoplasm of cells exposed to UVR (Figure $4 \mathrm{a}$ and Van der Houven van Oordt $\mathrm{W}^{19}$ ); therefore, UVR may cause a decrease in clAP1 mRNA stability (and thus clAP1 protein levels) because of this increase in cytoplasmic hnRNP A1. To test this hypothesis we used a mutant variant of hnRNP A1 that is defective in its interaction with the Trn1 transporter protein and thus fails to enter the nucleus and accumulates in the cytoplasm (the $\mathrm{F} 1$ mutant; ${ }^{20}$ ). Indeed, we found that the transient transfection of HEK293 cells with FLAG-tagged hnRNP A1 F1-expressing plasmid resulted in a significant reduction of clAP1 protein (Figure $4 \mathrm{~b}$ ). This was in contrast to cells transfected with FLAG-tagged wild type hnRNP A1, which had a negligible effect on the levels of clAP1 (Figure 4b). Thus, accumulation of hnRNP A1 in the cytoplasm, even in the absence of UVR, is sufficient to decrease the levels of ClAP1 protein.

We further hypothesized that any decrease in cIAP1 levels because of UVR should be dependent on hnRNP A1. Cells were co-transfected with a cIAP1 3'UTR reporter plasmid and either a non-silencing control siRNA or hnRNP A1-targeting siRNA, exposed to UVR $48 \mathrm{~h}$ later, and the levels of CAT reporter mRNA were determined by qRT-PCR $5 \mathrm{~h}$ post-irradiation. As observed earlier, exposure of cells to UVR significantly reduced the levels of CAT mRNA. Importantly, reduction of hnRNP A1 levels by siRNA restored CAT mRNA levels almost to the levels of a control mRNA that does not harbour the cIAP1 3'UTR (Figure 4c). Similarly, the decrease in endogenous clAP1 levels following UVR was also dependent on hnRNP A1, as transient reduction of hnRNP A1 allowed clAP1 levels to be maintained in response to UVR (Figure 4d; compare lanes 4 and 5). In contrast, transient reduction of TIAR, an RNA-binding protein that does not bind the clAP1 3'UTR (Figure 3a) had no effect on clAP1 protein levels following UVR (Supplementary Figure 2). To confirm that the stabilization of clAP1 protein levels in UV-irradiated cells is because of the stabilization of clAP1 mRNA we examined the steady-state levels of clAP1 mRNA. We observed that although UVR reduced clAP1 mRNA levels in control siRNA-transfected cells, transient knockdown of hnRNP A1 in UVR-treated cells allowed clAP1 mRNA to be maintained at levels seen in non-irradiated cells (Figure 4e). Together these results indicate that accumulation of hnRNP A1 in the cytoplasm following exposure of cells to UV irradiation causes a decrease in cIAP1 protein levels through the ability of the cytoplasmic hnRNP A1 to interact with the cIAP1 $3^{\prime} U T R$, resulting in destabilization of clAP1 mRNA.

hnRNP A1 modulates NF- $\kappa$ B signalling through destabilization of cIAP1 mRNA. It emerged recently that the primary role of clAP1 is to modulate NF- $\kappa$ B signalling. ${ }^{6-8}$ We therefore wished to examine whether the destabilization of clAP1 mRNA that is brought about by cytoplasmic 


\section{a}

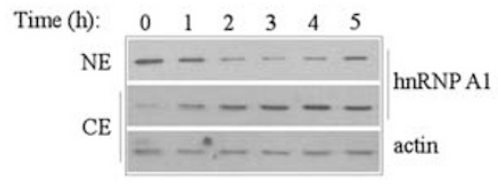

c
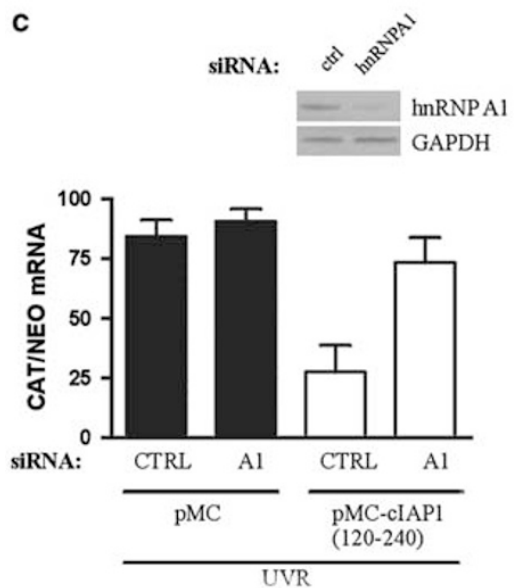

e

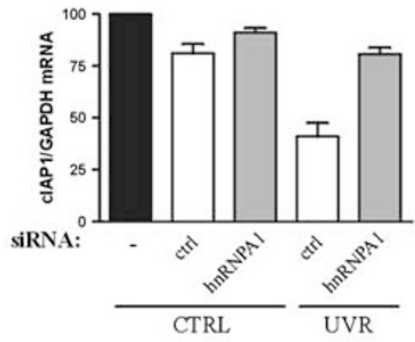

b

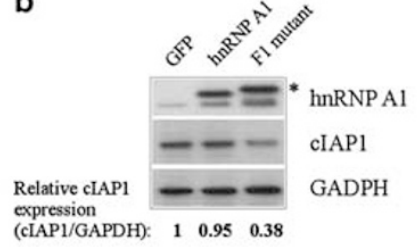

d

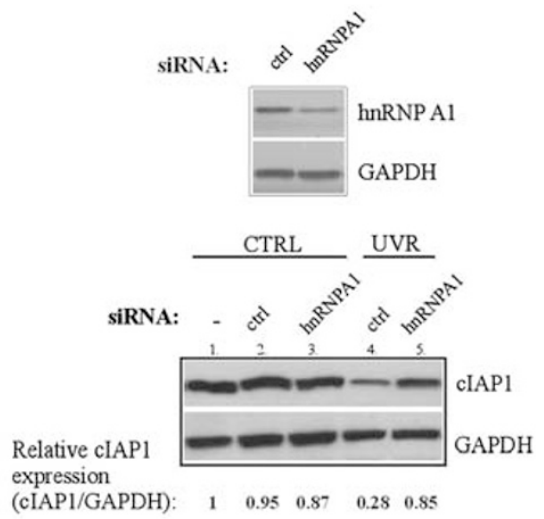

f

siRNA:
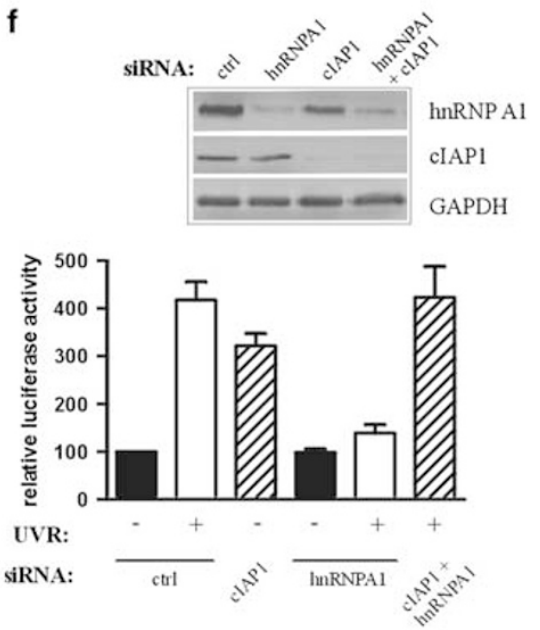

Figure 4 Cytoplasmic levels of hnRNP A1 regulate cIAP1 mRNA stability and NF- $\kappa$ B signalling following UV irradiation. (a) hnRNP A1 accumulates in the cytoplasm of UV-irradiated cells. 293 cells were exposed to UVR as described in Materials and Methods and the nuclear (NE) and cytoplasmic (CE) protein fractions were harvested at 1-h intervals post-UVR, separated by SDS-PAGE, transferred to PVDF, and subjected to western blot analysis with antibodies against hnRNP A1 and actin. (b) Cytoplasmic hnRNP A1 reduces cIAP1 protein levels. 293 cells were transfected with a plasmid-expressing GFP, FLAG-hnRNP A1, or FLAG-hnRNP A1 F1 mutant. Expression levels of FLAG-hnRNP A1, FLAG-hnRNP A1 F1, cIAP1 and GAPDH were determined by western blot analysis using anti-hnRNP A1, anti-clAP1, and anti-GAPDH antibodies. The asterisk $\left(^{*}\right)$ indicates the FLAG-tagged protein species. Relative cIAP1 levels are expressed as a ratio of cIAP1/GAPDH. The ratio in GFP-transfected cells was set as 1. (c) Reduced levels of hnRNP A1 stabilize cIAP1 $3^{\prime}$ UTR reporter mRNA following UVR. 293 cells were cotransfected with control non-silencing or hnRNP A1 siRNA and the indicated reporter plasmids. After $48 \mathrm{~h}$ the cells were UV-irradiated and the levels of CAT and NEO mRNA were determined by quantitative RT-PCR $5 \mathrm{~h}$ post-UVR. Values are expressed as CAT relative to NEO $\left(2^{-\left[C_{t}(C A T)-C_{t}(N E O)\right]}\right)$ and the ratio in non-irradiated cells transfected with control siRNA and the plasmid pMC was set as 100. The mean \pm S.D. of three independent experiments is shown. The levels of hnRNP A1 in cells transfected with control or hnRNP A1 siRNA were determined by western blot. (d) Reduced levels of hnRNP A1 increase endogenous clAP1 protein levels following UVR. 293 cells were transfected with control or hnRNP A1 siRNA as in (a) and the cells were irradiated $48 \mathrm{~h}$ later. Cell lysates were prepared $24 \mathrm{~h}$ post-UVR and the levels of clAP1 and GAPDH were determined by western blot. Relative clAP1 levels are expressed as a ratio of CIAP1/GAPDH. The ratio in mock-transfected non-irradiated cells was set as 1. Displayed data are representative of three independent experiments. (e) Reduced levels of hnRNP A1 stabilize clAP1 mRNA following UVR. 293 cells were treated as in (d) and the total RNA was extracted $5 \mathrm{~h}$ post-UVR. The levels of cIAP1 and GAPDH mRNA were determined by quantitative RT-PCR analysis. Values are expressed as CIAP1 relative to GAPDH $\left(2^{-\left[\mathcal{G}_{\mathrm{t}}(\mathrm{ClAP} 1)-\mathcal{G}_{\mathrm{t}}(\mathrm{GAPDH})\right]}\right)$ and the ratio in non-irradiated mocktransfected cells was set as 100. The mean \pm S.D. of three independent experiments is shown. (f) hnRNP A1 levels affect NF- $\kappa B$ signalling following UVR. 293 cells were cotransfected with control, hnRNP A1, or clAP1 siRNA and the NF- $\kappa$ B reporter plasmid pNF- $\kappa$ B-Luc as described in Materials and Methods. After $48 \mathrm{~h}$ the cells were UV-irradiated and luciferase levels were determined $18 \mathrm{~h}$ post-UVR. Values are presented as mean luminescence corrected to the number of live cells per plate. The relative luciferase activity in non-irradiated mock-transfected cells was set as 100. The mean \pm S.D. of three independent experiments is shown. The levels of hnRNP A1, clAP1 and GAPDH were determined by western blot analysis in parallel untreated samples 
accumulation of hnRNP A1 following exposure of cells to UVR affects NF- $\kappa$ B signalling. To quantitate changes in total $\mathrm{NF}-\kappa \mathrm{B}$ activity we co-transfected cells with a commercially available $\mathrm{NF}-\kappa \mathrm{B}$-luciferase reporter plasmid and siRNAtargeting clAP1, hnRNPA1 or non-targeting siRNA as a control. Following transfection cells were allowed to recover for $48 \mathrm{~h}$ and then exposed to UVR. Relative luciferase activity was determined $18 \mathrm{~h}$ post-UV irradiation, and the levels of clAP1 and hnRNP A1 were assessed by western blot analysis. We observed that UVR enhanced the basal $\mathrm{NF}-\kappa \mathrm{B}$ reporter activity (Figure $4 \mathrm{f}$ ) as shown earlier. ${ }^{21}$ Also as expected, transient knockdown of clAP1 had a similar effect and enhanced the basal NF- $\kappa \mathrm{B}$ reporter activity in the absence of UV irradiation (Figure 4f). In contrast, transient reduction of hnRNP A1 levels prevented the UVRmediated induction of $\mathrm{NF}-\kappa \mathrm{B}$ reporter activity. Importantly, the attenuation of $\mathrm{NF}-\kappa \mathrm{B}$-activity seen in UVR-treated and hnRNP A1 siRNA-transfected cells is dependent on clAP1 levels, as concomitant reduction of hnRNP A1 and clAP1 levels by siRNA resulted in enhanced $N F-\kappa B$ reporter expression. Taken together these results confirm that clAP1 levels are required for proper NF- $\kappa \mathrm{B}$ signalling activity $^{6-8}$ and uncover a role for the cytoplasmic accumulation of hnRNP A1 in this pathway following exposure of cells to UV irradiation.

\section{Discussion}

An important finding of this study is that UV irradiation reduces the expression of clAP1, a member of the inhibitor of apoptosis family of proteins and a critical regulator of NF- $\kappa \mathrm{B}$ signalling. We demonstrated that UVR results in a $40 \%$ decrease in the half-life of clAP1 mRNA. Examination of the $3^{\prime}$ UTR of clAP1 revealed the presence of four AU-rich elements, two of which are sufficient and necessary to confer instability on a reporter mRNA. Furthermore, we have identified hnRNP A1 as a stress-regulated cIAP1 ARE-binding protein. Importantly, cytoplasmic relocalization of hnRNP A1 triggered by UV irradiation causes a significant reduction in clAP1 mRNA levels and a concomitant decrease in the level of endogenous clAP1 protein. On the basis of these findings we conclude that hnRNP $A 1$ is a negative regulator of clAP1 expression and thus contributes to the regulation of NF- $\kappa \mathrm{B}$ signalling following UV stress. In addition, our findings strengthen the hypothesis that post-transcriptional control of gene expression can be exercised through subcellular relocalization of mRNA-binding proteins.

The regulation of mRNA decay is a central mechanism for the control of gene expression and is mediated by distinct RNA regulatory elements. AREs are one such class of elements and are found in the $3^{\prime}$ UTRs of specific mRNAs. Although initially believed to be restricted to mRNAs of genes encoding cytokines, growth factors and oncogenes, recent data suggest that ARE occurrence is much more prevalent, possibly in as much as $8 \%$ of the human transcriptome. ${ }^{22}$ AREs typically function as RNA-destabilizing elements that target mRNA for rapid degradation in the cytoplasm. ${ }^{23}$ We have identified four AU-rich sequences within the $3^{\prime} U T R$ of clAP1. Mutational analysis revealed that only the last two segments, ARE no. 3 and ARE no. 4, are required for the instability conferred by clAP1 3'UTR (Figure 3). AREs in general contain multiple copies of $A / U$ nucleotides, ${ }^{23}$ and the clAP1 3 UTR thus appears to be a typical example of this class of regulatory sequences.

AREs exert their effect on target mRNAs through interaction with specific mRNA-binding proteins. We identified hnRNP A1 as a clAP1 $3^{\prime}$ UTR-binding protein (Figure 3 ). This is in contrast to TIAR, TIA-1, or hnRNP C1/C2 (known AREbinding proteins), which were not found to interact with clAP1 3'UTR. Furthermore, the direct interaction of hnRNP A1 with clAP1 3'UTR was demonstrated by in vitro crosslinking and filter-binding assays. Importantly, binding of hnRNP A1 correlates with the instability of clAP1 $3^{\prime} U T R$-containing mRNA, providing strong evidence that hnRNP A1 functions as a major destabilizing factor for clAP1 mRNA. hnRNP A1 is a multifunctional protein that is implicated in diverse steps of RNA metabolism including splicing, ${ }^{24}$ mRNA stability ${ }^{25}$ and translation. ${ }^{17}$ hnRNP A1 has been previously shown to bind several labile mRNAs that contain the AUUUA sequence, including the granulocyte-macrophage colony-stimulating factor (GM-CSF), ${ }^{25}$ human angiotensin receptor $\mathrm{AT}_{1},{ }^{26}$ and cytochromes $\mathrm{P} 450,2 \mathrm{~A} 6$ and $2 \mathrm{~A} 5 .^{27,28} \mathrm{~A}$ similar AUUUA sequence is found in ARE no. 1, ARE no. 2, and ARE no. 3 of the cIAP1 3'UTR. Surprisingly, using mutational analysis we find that only ARE no. 3 and ARE no. 4 are bound by hnRNP $A 1$, and that the presence of both intact sequences is required for binding (Figure 3). Mutations that abolished binding of hnRNP A1 resulted in stabilization of reporter mRNA. ARE no. 1 , in which the AUUUA pentanucleotide is embedded within a larger stretch of $A / U$ nucleotides exhibited only partial binding to hnRNP A1, and the reporter mRNA carrying this mutation was partially stabilized. It has been recognized that the binding of proteins to AREs is dependent on both the primary sequence and sequence context, and that the presence of AUUUA in itself does not guarantee a functional ARE. ${ }^{23}$ This applies to the nature of the CIAP1 AREs within the $3^{\prime}$ UTR and their surrounding sequence. In addition, a permissive secondary structure of the $3^{\prime}$ UTR and proper presentation of the ARE for the ARE-binding protein are thought to contribute to the function of AREs. For example, the RNA-binding protein HuR requires both the presence of the HuR-binding site within the ARE as well as the presentation of this site in a singlestranded conformation within the $3^{\prime}$ UTR structure for proper binding. ${ }^{29}$ Although hnRNP A1 is usually considered an RNA and single-stranded DNA-binding protein, ${ }^{30}$ accumulated evidence indicates that hnRNP $A 1$ is capable of binding double-stranded DNA and RNA regions as well. In fact it was shown that hnRNP A1 could bind simultaneously to bipartite sequence elements with its two RRM domains, or as a dimer. ${ }^{31-33}$ Our data fits well with this model suggesting that simultaneous contact of hnRNP A1 with ARE no. 3 and ARE no. 4 is required for proper binding of hnRNP A1 to clAP1 $3^{\prime}$ UTR. Thus, mutations in either one of these sites would result in the attenuation of binding and consequent stabilization of the mRNA, as we have observed.

hnRNP A1 is predominantly a nuclear protein involved in the regulation of splicing. ${ }^{34}$ However, hnRNP A1 has been shown to shuttle from the nucleus to the cytoplasm, where it exhibits a different ligand specificity, thus leading to the postulation that cytoplasmic hnRNP A1 performs roles distinct 
from splicing. ${ }^{34}$ Indeed, recent experimental data implicate hnRNP A1 in the regulation of mRNA translation, turnover, and viral replication. The subcellular localization of hnRNP A1 is dictated by the phosphorylation status of its $C$ terminus, which affects the Trn1-dependent nuclear import of hnRNP A1. ${ }^{20}$ The phosphorylation of hnRNP A1 occurs under conditions of diverse stresses such as osmotic shock, ${ }^{19}$ UV irradiation, ${ }^{19}$ heat shock, ${ }^{35}$ or treatment of cells with sodium butyrate ${ }^{36}$ and arsenite. $^{35}$ Cytoplasmic hnRNP A1 accumulates in stress granules, the sites of mRNA triage from which target mRNAs are exported to processing bodies for degradation. ${ }^{35}$ Congruent with this model we find that CIAP1 mRNA and reporter mRNA harbouring the $3^{\prime} U T R$ of clAP1 is rapidly degraded upon irradiation of cells with UV (Figures 1 and 2), conditions that result in an accumulation of hnRNP A1 in the cytoplasm. This reduction in clAP1 levels can be reversed by transient knockdown of hnRNP A1 (Figure 4d) confirming that the repression of clAP1 expression following UVR is dependent on hnRNP A1. It is important to note that under normal conditions hnRNP A1 is predominantly present in the nucleus, and thus depletion of hnRNP A1 in untreated cells would be predicted to have only a minimal effect on clAP1 levels, as we have indeed observed (Figure 4d).

Ultraviolet radiation is a common environmental stress that causes DNA damage and induces cell death in mammalian cells. ${ }^{37}$ Previous work showed that exposure of cells to UVR results in an inhibition of global protein synthesis. ${ }^{14,38,39}$ This observation leads to the question of why an additional regulatory mechanism, such as degradation of clAP1 mRNA, would be employed by cells to silence the expression of target genes following UVR. It is interesting to note that several genes involved in the regulation of cell proliferation and survival are translated by an IRES-dependent mode of translation that escapes some of the control steps that govern global, cap-dependent translation. For example, translation of the apoptosis protease-activating factor Apaf- 1 is driven by an IRES element activity that is enhanced following UVR. ${ }^{14}$ We and others have shown previously that translation of cIAP1 is also driven by an IRES. ${ }^{12,40}$ Importantly, clAP1 IRES activity is induced by cellular stresses such as endoplasmic reticulum stress, ${ }^{12}$ etoposide,$^{40}$ and sodium arsenite. ${ }^{40}$ As cIAP1 IRES would allow bypass of the global inhibition of protein synthesis induced by UVR and thus continued expression of ClAP1 protein, the degradation of CIAP1 mRNA by an hnRNP A1-dependent mechanism following UVR can be viewed as an additional control step aimed at the reduction of clAP1 levels and a return to homeostasis.

Recent evidence suggests that the primary cellular role of clAP1 is to regulate NF- $\kappa$ B signalling, as specific degradation of clAP1 results in activation of both the canonical and noncanonical NF- $\kappa$ B signalling pathways. ${ }^{6-8} \mathrm{NF}-\kappa \mathrm{B}$ plays a critical role in cell proliferation and apoptosis, and activation of $\mathrm{NF}-\kappa \mathrm{B}$ by UV irradiation is an important protective mechanism for mammalian cells. ${ }^{21}$ However, the molecular mechanisms involved in the activation of NF- $\kappa$ B following UV irradiation are poorly understood. Our data provide new insight into the regulation of $\mathrm{NF}-\kappa \mathrm{B}$-signalling pathways and suggest a mechanism in which targeted degradation of clAP1 mRNA, and thus a reduction in clAP1 protein, is mediated by cytoplasmic accumulation of hnRNP A1 in response to UV irradiation.

\section{Materials and Methods}

Cell culture and reagents. Human embryonic kidney (HEK293), or human cervical carcinoma (HeLa) cells were maintained in standard conditions in Dulbecco's modified Eagle's medium (DMEM; Wisent Inc.) supplemented with heat inactivated $10 \%$ fetal calf serum (FCS), $2 \mathrm{mM}$ L-glutamine and $1 \%$ antibiotics (100 U/ml penicillin-streptomycin). Transient transfections were performed using LipofectAMINE PLUS reagent (Invitrogen; Carlsbad, CA, USA) according to the manufacturer's protocol. Briefly, cells were seeded at a density of $6 \times 10^{5}$ cells per well in 6 -well plates and were transfected $24 \mathrm{~h}$ later in serum-free OPTI-MEM medium (Invitrogen) with $0.5 \mu \mathrm{g}$ of DNA per well. The transfection mixture was supplemented $3 \mathrm{~h}$ later with $1 \mathrm{ml}$ DMEM containing $10 \%$ fetal calf serum, glutamate, and antibiotics. Cells were collected for analysis $24 \mathrm{~h}$ after transfection. siRNA transfections were performed using Lipofectamine 2000 reagent (Invitrogen) according to the protocol provided by the manufacturer. Briefly, cells were seeded at a density of $3 \times 10^{5}$ cells per well in 6-well plates and were transfected $24 \mathrm{~h}$ later in serum-free DMEM with either a $10 \mathrm{nM}$ final concentration of hnRNP A1 or TIAR siRNA (Santa Cruz Biotechnology, Santa Cruz, CA, USA), a $5 \mathrm{nM}$ final concentration of HIAP2 siRNA (Dharmacon) or a nonsilencing scrambled control siRNA (Qiagen). Cells were collected for analysis $48 \mathrm{~h}$ after transfection. In the case of co-transfections, $0.5 \mu \mathrm{g}$ per well of reporter plasmid DNA was co-transfected at the same time as siRNA.

For UV irradiation (UVR) experiment cells were seeded at a density of $6 \times 10^{5}$ cells per well in 6 -well plates. After $24 \mathrm{~h}$, cells were washed with phosphatebuffered saline (PBS) and irradiated at room temperature in $2 \mathrm{ml}$ fresh medium with a 30-watt UVC light source $(254 \mathrm{~nm})$ with the cover removed. After irradiation, cells were further incubated in culture medium for the indicated times and harvested. PBS washed cells not exposed to UVR served as controls. The intensity of UVR was measured prior to each experiment with a UVX radiometer (UVP Inc., Upland, CA USA). For the Actinomycin D (ActD) experiments, cells were treated with $10 \mu \mathrm{g} / \mu \mathrm{l}$ of ActD immediately following UVR $\left(150 \mathrm{~mW} / \mathrm{cm}^{2}\right)$ and harvested $0,1,2,4,8 \mathrm{~h}$ later. Cells not treated with UVR served as a control. Cells transfected with a siRNA were treated with UVR $\left(150 \mathrm{~mW} / \mathrm{cm}^{2}\right) 48 \mathrm{~h}$ post-siRNA transfection and harvested $5 \mathrm{~h}$ later, as described above.

The expression plasmid pMC was constructed by inserting a synthetic polylinker (5'-AGC TTG CGG CCG CTA GCC TCG AGG GAT CCT CTA GAA TGC A-3') into a pcDNA3 vector (Invitrogen) followed by insertion of the chloramphenicol acetyl transferase (CAT) coding sequence. The CAT insert was generated by PCR amplification using PCAT as a template. The $3^{\prime}$ UTRs were generated by $P C R$ amplification from a liver cDNA library (Invitrogen). Expression plasmids pMC-cIAP1-FL and pMC-TNF $\alpha$ were thus constructed by inserting the $3^{\prime} U T R$ of CIAP1, and TNF $\alpha$, respectively downstream of CAT in the pMC construct. Deletion derivatives of pMC-cIAP1-FL were generated using a similar method; CIAP1 $3^{\prime}$ UTR segments were PCR amplified and cloned into pMC. The primers for amplification of respective $3^{\prime} U T R$ fragments are listed in Table 1. The site-directed mutagenesis of CIAP1 $3^{\prime}$ UTR was carried out using the Quickchange II site-directed mutagenesis kit (Stratagene) following the manufacturer's instructions. All plasmid constructs were confirmed by nucleotide sequencing. FLAG-hnRNP A1 and FLAG-hnRNP A1 F1 expression plasmids were described earlier. ${ }^{17}$

Table 1 The sequences of primers used in this study to amplify $3^{\prime} U T R s$

$T N F \alpha$ :

Forward primer: 5'-GGA TCC GGA GGA CGA ACA TCC AAC CTT' Reverse primer: $5^{\prime}$-TCT AGA CTA AGC AAA CTT TAT TTC TCG cIAP1-FL:

Forward primer: 5'-GGA TCC AGA AAA ATA GTC TAT ATT TTA AC Reverse primer: 5'-TCT AGA CAC TTT ATT GAG ATG TTT CTC AC cIAP1 (4-120):

Forward primer: $5^{\prime}$-GGA TCC AGA AAA ATA GTC TAT ATT TTA AC Reverse primer: 5'-TCT AGA GTA CCA AAG CAG ACT AGA AC clAP1 (120-240):

Forward primer: 5'-GGA TCC GTT CTA GTC TGC TTT GGT AC Reverse primer: 5'-TCT AGA CAG TGA CAC TAC TCC CTT AGG cIAP1 (240-480):

Forward primer: $5^{\prime}-\mathrm{GGA}$ TCC CCT AAG GGA GTA GTG TCA CTG Reverse primer: 5'-TCT AGA CAC TTT ATT GAG ATG TTT CTC AC 
Western blot analysis. Cells were washed in $1 \mathrm{ml}$ of ice-cold PBS and lysed in $150 \mu \mathrm{l}$ RIPA buffer (1\% Nonidet P-40, $1 \%$ sodium deoxycholate, $0.1 \%$. SDS $150 \mathrm{mM} \mathrm{NaCl}, 10 \mathrm{mM}$ sodium phosphate (pH 7.2), $2 \mathrm{mM}$ EDTA, $0.1 \mathrm{mM}$ phenylmethylsulphonyl fluoride) containing $10 \mu \mathrm{g} / \mathrm{ml}$ each of aprotinin, pepstatin A and leupeptin (all from Sigma) for $30 \mathrm{~min}$ at $4{ }^{\circ} \mathrm{C}$, followed by centrifugation at $14000 \times g$ for $10 \mathrm{~min}$ and supernatants were collected. Protein concentration in the supernatants was determined by a protein assay kit (Bradford; Bio-Rad, Richmond, CA, USA), and equal amounts of protein extract were separated by $10 \%$ SDS-PAGE. Proteins were subsequently transferred onto PVDF membrane and analyzed by western blotting with the following antibodies: rabbit polyclonal anticIAP1 (abCAM), mouse-monoclonal anti-GAPDH (Advanced ImmunoChemical), mouse-monoclonal anti TIA-1/TIAR (clone 3E6; generous gift from P. Anderson), mouse monoclonal anti-hnRNP C (clone 4F4, generous gift from $G$. Dreyfuss), and goat polyclonal anti-hnRNP A1 (Santa Cruz Biotechnology). All antibodies were used at the manufacturer's suggested dilutions and conditions followed by secondary antibody (horseradish peroxidase-conjugated sheep anti-mouse, antigoat or anti-rabbit IgG; GE Healthcare, Piscataway, NJ, USA). Antibody complexes were detected using the ECL Plus and ECL western blotting detection systems (GE Healthcare). For the purposes of quantification of protein expression, parallel western blots were performed as described above but the secondary antibody used was Alexa Fluor 680-coupled goat anti-mouse, or anti-rabbit IgG (LI-Cor Inc.). Antibody complexes were then detected and quantified using the Odyssey Infrared Imaging system (LI-Cor Inc.). All quantification data are shown as an average \pm S.D. from at least three independent experiments. As some confusion exists in the literature as to the specificity of the cIAP1 Abcam antibody, we have verified that the antibody used in this study specifically detects CIAP1 but not cIAP2 (Supplementary Figure 1).

Subcellular fractionation. Cells were washed in $1 \mathrm{ml}$ of ice-cold PBS, resuspended in $400 \mu$ of Buffer A ( $10 \mathrm{mM} \mathrm{HEPES}-\mathrm{KOH}$ (pH 7.5), $10 \mathrm{mM} \mathrm{KCl}, 1 \mathrm{mM}$ DTT, $1 \mathrm{mM}$ PMSF) containing protease inhibitors, and incubated on ice for $15 \mathrm{~min}$. Nonidet P-40 was added to a final concentration of $0.3 \%$ and cells were incubated for an additional $10 \mathrm{~min}$ on ice. Nuclei were pelleted by centrifugation at $1500 \times \mathrm{g}$ for $5 \mathrm{~min}$, the cytoplasmic fraction was collected to a new tube and clarified by centrifugation at $13000 \times \mathrm{g}$ for $15 \mathrm{~min}$. The nuclei pellet was washed $2 \times$ with $1 \mathrm{ml}$ of Buffer $\mathrm{A}$, and then resuspended in $50 \mu \mathrm{l}$ of Buffer B (20 mM HEPES-KOH (pH 7.5), $400 \mathrm{mM} \mathrm{NaCl}, 1 \mathrm{mM}$ DTT, $1 \mathrm{mM}$ PMSF) containing protease inhibitors and incubated on ice for $30 \mathrm{~min}$, with mixing every $5 \mathrm{~min}$. Nuclear debris was pelleted at $13000 \times \mathrm{g}$ for $5 \mathrm{~min}$ and the nuclear fraction was collected to a new tube.

Pulse-chase immunoprecipitation. HEK293 $\left(6 \times 10^{5}\right)$ cells were seeded in 6 -well plates $24 \mathrm{~h}$ prior to UV irradiation. Cells were incubated with DMEM lacking methionine and cysteine and supplemented with 10\% FCS for 15 min at $37^{\circ} \mathrm{C}$. Cells were then irradiated with UVC as described above and pulselabelled with $0.1 \mathrm{mCi} / \mathrm{ml}^{35} \mathrm{~S}$-methionine and cysteine mix (EasyTag ${ }^{\text {TM }}$ EXPRESS Protein Labelling Mix, PerkinElmer) for 25 min at $37^{\circ} \mathrm{C}$. Labelled cells were washed once in PBS and chased with cold methionine/cysteine-containing DMEM. At indicated time points cells were harvested in cold PBS and boiled in $50 \mu \mathrm{l}$ of denaturing lysis buffer ( $50 \mathrm{mM}$ Tris, pH 7.4, $5 \mathrm{mM}$ EDTA, $1 \%$ SDS, $10 \mathrm{mM}$ DTT $1 \mathrm{mM}$ PMSF, $2 \mu \mathrm{g} / \mathrm{ml}$ leupeptin, $15 \mathrm{U} / \mathrm{ml}$ DNasel) for $5 \mathrm{~min}$. A cold non-denaturing buffer of $450 \mu \mathrm{l}$ ( $50 \mathrm{mM}$ Tris, pH 7.4, $5 \mathrm{mM}$ EDTA, $300 \mathrm{mM} \mathrm{NaCl}, 1 \%$ Triton X-100, $10 \mathrm{mM}$ iodoacetamide, $1 \mathrm{mM}$ PMSF, $2 \mu \mathrm{g} / \mathrm{ml}$ leupeptin) was then added and the lysate was passed through a $25-\mathrm{G}$ syringe needle 10 times. Following centrifugation to remove debris, the lysate was pre-cleared prior to immunoprecipitation with Pansorbin ${ }^{\circledR}$ cells (Calbiochem) for $2 \mathrm{~h}$ at $4{ }^{\circ} \mathrm{C}$. Co-immunoprecipitation of cIAP1 and $\beta$-actin from the pre-cleared lysates was performed at $4{ }^{\circ} \mathrm{C}$ for $16 \mathrm{~h}$ using Protein G/Protein A-Agarose beads (Calbiochem) coated with antibodies specific for $\beta$-actin and CIAP1 at a dilution of $1: 500$ and $1: 150$, respectively. The beads were then washed extensively with cold wash buffer $(50 \mathrm{mM}$ Tris, $\mathrm{pH} 7.4,300 \mathrm{mM} \mathrm{NaCl}$, $0.1 \%$ Triton X-100), resuspended in Laemmli buffer and boiled to elute bound proteins. Immunoprecipiated proteins or total proteins were then resolved on $10 \%$ SDS-PAGE and stained with PageBlue ${ }^{\mathrm{TM}}$ (Fermentas) Coomassie stain. The gel was incubated with Amplify fluorogenic reagent (GE Biosciences) for 30 min prior to drying and exposure to film.

mRNA stability analysis. Cells were treated or not with UVR $\left(150 \mathrm{~mW} / \mathrm{cm}^{2}\right)$ as described above and Actinomycin $D(10 \mu \mathrm{g} / \mu \mathrm{l})$ was then added immediately to each well. Total RNA was isolated using the Absolutely RNA miniprep kit (Stratagene) at 0 (immediately after adding the Actinomycin D), 2, 4, 8, 12 and $16 \mathrm{~h}$
Table 2 The sequences of quantitative RT-PCR primers used in the study

cIAP1:

Forward primer: 5'-TCT GGA GAT GAT CCA TGG GTA GA

Reverse primer: $5^{\prime}$-TGG CCT TTC ATT CGT ATC AAG A GAPDH:

Forward primer: 5'-ACA GTC AGC CGC ATC TTC TT

Reverse primer: 5'-ACG ACC AAA TCC GTT GAC TC

NEO:

Forward primer: $5^{\prime}$-TGA ATG AAC TGC AGG ACG AG

Reverse primer: 5'-CAA TAG CAG CCA GTC CCT TC

CAT:

Forward primer: 5'-GCG TGT TAC GGT GAA AAC CT

Reverse primer: 5'-GGG CGA AGA ACT TGT CCA TA

time points and the levels of clAP1 and GAPDH mRNA was determined by quantitative RT-PCR as described below.

Quantitative RT-PCR. Total RNA was isolated using the Absolutely RNA miniprep kit (Stratagene) following manufacturer's instructions. For quantitative RT$\mathrm{PCR}$, reverse transcription was carried out using the First-Strand cDNA Synthesis kit (GE Healthcare) with oligo $\mathrm{d}(\mathrm{T})_{18}$ primers. The quantitative PCR was performed using the QuantiTect SYBR green PCR kit (Qiagen) and analysed on an ABI Prism 7000 sequence detection system using the ABI Prism 7000 SDS Software. Quantitative PCRs were carried out to detect CIAP1, GAPDH, CAT and NEO genes using primers listed in Table 2. Average data from at least three experiments \pm S.D

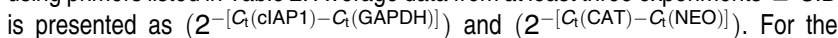
Actinomycin $D$ experiment, $\left(2^{-\left[C_{t}(\mathrm{CIAP} 1)-C_{t}(\mathrm{GAPDH})\right]}\right)$ normalized to $0 \mathrm{~h} C_{\mathrm{t}}$ values $\left(2^{-\Delta \Delta C_{T}}\right)$ is shown.

RNA-affinity chromatography. Identification of cIAP1 3'UTR RNA-binding proteins was performed as described earlier. ${ }^{17}$ Briefly, in vitro transcribed cIAP1 $3^{\prime}$ UTR RNA was biotinylated at the $5^{\prime}$ end with the $5^{\prime}$ EndTag Nucleic Acid Labeling System according to the manufacturer's instructions (Vector Laboratories). The biotinylated RNA (10 $\mu \mathrm{g})$ was conjugated to Avidin-agarose beads (Sigma) in the presence of incubation buffer ( $10 \mathrm{mM}$ Tris- $\mathrm{Cl}(\mathrm{pH} 7.4), 150 \mathrm{mM} \mathrm{KCl}, 1.5 \mathrm{mM} \mathrm{MgCl}_{2}$, $0.5 \mathrm{mM}$ DTT, $0.5 \mathrm{mM}$ phenylmethylsulphonyl fluoride, $0.05 \%$ (v/v) Nonidet P-40) at $4{ }^{\circ} \mathrm{C}$ for $2 \mathrm{~h}$ with continuous rotation. Unbound RNA was removed by washing the beads two times with incubation buffer. A $293 \mathrm{~T}(500 \mu \mathrm{g})$ protein extract (in incubation buffer) was added to the coated beads, along with $30 \mu \mathrm{g}$ yeast tRNA (Sigma) and 200 units of Prime RNase inhibitor (Eppendorf). Reactions were incubated at room temperature with continuous rotation for $30 \mathrm{~min}$, followed by incubation at $4{ }^{\circ} \mathrm{C}$ with continuous rotation for $2.5 \mathrm{~h}$. Beads were washed five times with $500 \mu \mathrm{l}$ incubation buffer, resuspended in $20 \mu \mathrm{l}$ of $1 \times$ SDS-PAGE loading dye, and boiled for $5 \mathrm{~min}$ to elute bound proteins. Proteins were separated by $10 \%$ SDSPAGE and detected by western blot analysis.

UV crosslinking of RNA-protein complexes and nitrocellulose filter-binding assay. RNA-protein UV-crosslinking experiments were performed using purified GST-hnRNP A1 and $\left.{ }^{32} \mathrm{P}\right]$-labeled cIAP1 3 'UTR RNA as described earlier. ${ }^{17}$.Similarly, the filter-binding assays were performed using the purified GST-hnRNP A1 as described. ${ }^{17}$

NF- $\kappa$ B reporter assay. A reporter plasmid containing NF- $\kappa B$ enhancer elements upstream of a luciferase reporter gene (pNF- $\kappa B$-Luc, Stratagene) was used to assess NF- $\kappa$ B activity in HEK293T following exposure to UVR. Cells seeded in 6-well plates were transfected with DNA and/or siRNA as described above. After $24 \mathrm{~h}$ the cells were exposed to UVR $\left(150 \mathrm{~mW} / \mathrm{cm}^{2}\right)$ followed by incubation at $37^{\circ} \mathrm{C}$ for $18 \mathrm{~h}$. To measure luciferase activity, $200 \mathrm{ng} / \mathrm{ml}$ of D-luciferin (BD Biosciences) was added to the cell media and incubated for $5 \mathrm{~min}$ at room temperature. Luminescence was recorded using the IVIS Imaging system (Xenogen) and quantified with IVIS Liveimage 2.5 software. Values are presented as mean luminescence corrected to the number of cells per plate.

Acknowledgements. This work was supported by a discovery grant from the National Sciences and Engineering Research Council of Canada (NSERC). J.C. is the recipient of Canada Research Chair (Tier 2) in RNA Metabolism. I.G. is 
supported by a scholarship from Fonds pour la Recherche en Santé du Québec (FRSQ). T.E.G. is supported by the Frederick Banting and Charles Best Canada Graduate Scholarships Doctoral Award. M.H. is the CHEO Volunteer Association Endowed Scholar.

1. Salvesen GS, Duckett CS. Apoptosis: IAP proteins: blocking the road to death's door. Nat Rev Mol Cell Biol 2002; 3: 401-410.

2. Vaux DL, Silke J. IAPs, RINGs and ubiquitylation. Nat Rev Mol Cell Biol 2005; 6: 287-297.

3. Eckelman BP, Salvesen GS, Scott FL. Human inhibitor of apoptosis proteins: why XIAP is the black sheep of the family. EMBO Rep 2006; 7: 988-994.

4. Rothe M, Pan MG, Henzel WJ, Ayres TM, Goeddel DV. The TNFR2-TRAF signaling complex contains two novel proteins related to baculoviral inhibitor of apoptosis proteins. Cell 1995; 83: 1243-1252.

5. Li X, Yang Y, Ashwell JD. TNF-RII and c-IAP1 mediate ubiquitination and degradation of TRAF2. Nature 2002; 416: 345-347.

6. Vince JE, Wong WW, Khan N, Feltham R, Chau D, Ahmed AU et al. IAP antagonists target clAP1 to induce TNF alpha-dependent apoptosis. Cell 2007; 131: 682-693.

7. Petersen SL, Wang L, Yalcin-Chin A, Li L, Peyton M, Minna J et al. Autocrine TNF alpha signaling renders human cancer cells susceptible to Smac-mimetic-induced apoptosis. Cancer Cell 2007; 12: 445-456.

8. Varfolomeev E, Blankenship JW, Wayson SM, Fedorova AV, Kayagaki N, Garg P et al. IAP Antagonists Induce autoubiquitination of c-IAPs, NF-kappaB Activation, and TNFalpha-Dependent Apoptosis. Cell 2007; 131: 669-681.

9. Wang CY, Mayo MW, Korneluk RG, Goeddel DV, Baldwin Jr AS. NF-kappaB antiapoptosis: induction of TRAF1 and TRAF2 and C-IAP1 and c-IAP2 to suppress caspase-8 activation. Science 1998; 281: 1680-1683

10. Conze DB, Albert L, Ferrick DA, Goeddel DV, Yeh WC, Mak T et al. Posttranscriptional downregulation of C-IAP2 by the ubiquitin protein ligase c-IAP1 in vivo. Mol Cell Biol 2005; 25: 3348-3356.

11. Warnakulasuriyarachchi $\mathrm{D}$, Ungureanu $\mathrm{NH}$, Holcik $\mathrm{M}$. The translation of an antiapoptotic protein HIAP2 is regulated by an upstream open reading frame. Cell Death Differ 2003; 10 899-904.

12. Warnakulasuriyarachchi $\mathrm{D}$, Cerquozzi $\mathrm{S}$, Cheung $\mathrm{HH}$, Holcik M. Translational induction of the inhibitor of apoptosis protein HIAP2 during endoplasmic reticulum stress attenuates cel death and is mediated via an inducible internal ribosome entry site element. J Biol Chem 2004; 279: 17148-17157.

13. Yoshimura FK, Luo X, Zhao X, Gerard HC, Hudson AP. Up-regulation of a cellular protein at the translational level by a retrovirus. Proc Natl Acad Sci USA 2008; 105: 5543-5548.

14. Ungureanu NH, Cloutier M, Lewis SM, de Silva N, Blais JD, Bell JC et al. Internal ribosome entry site-mediated translation of Apaf-1, but not XIAP, is regulated during UV-induced cell death. J Biol Chem 2006; 281: 15155-15163.

15. Kim JH, Paek KY, Ha SH, Cho S, Choi K, Kim CS et al. A cellular RNA-binding protein enhances internal ribosomal entry site-dependent translation through an interaction Downstream of the hepatitis C virus polyprotein initiation codon. Mol Cell Biol 2004; 24 7878-7890.

16. Bonnal S, Pileur F, Orsini C, Parker F, Pujol F, Prats AC et al. Heterogeneous nuclear ribonucleoprotein $A 1$ is a novel internal ribosome entry site trans-acting factor that modulates alternative initiation of translation of the fibroblast growth factor 2 mRNA. J Biol Chem 2005; 280: 4144-4153.

17. Lewis SM, Veyrier A, Hosszu Ungureanu N, Bonnal S, Vagner S, Holcik M. Subcellular relocalization of a trans-acting factor regulates XIAP IRES-dependent translation. Mol Biol Cell 2007; 18: 1302-1311.

18. Cammas A, Pileur F, Bonnal S, Lewis SM, Leveque N, Holcik M et al. Cytoplasmic relocalization of heterogeneous nuclear ribonucleoprotein $\mathrm{A} 1$ controls translation initiation of specific mRNAs. Mol Biol Cell 2007; 18: 5048-5059.

19. van der Houven van Oordt W, Diaz-Meco MT, Lozano J, Krainer AR, Moscat J, Caceres JF. The MKK(3/6)-p38-signaling cascade alters the subcellular distribution of hnRNP A1 and modulates alternative splicing regulation. J Cell Biol 2000; 149: 307-316.
20. Allemand E, Guil S, Myers M, Moscat J, Caceres JF, Krainer AR. Regulation of heterogenous nuclear ribonucleoprotein $\mathrm{A} 1$ transport by phosphorylation in cells stressed by osmotic shock. Proc Natl Acad Sci USA 2005; 28: 28.

21. Bender K, Gottlicher M, Whiteside S, Rahmsdorf HJ, Herrlich P. Sequential DNA damageindependent and -dependent activation of NF-kappaB by UV. EMBO J 1998; 17 5170-5181.

22. Khabar KS, Bakheet T, Williams BR. AU-rich transient response transcripts in the human genome: expressed sequence tag clustering and gene discovery approach. Genomics 2005; 85: 165-175.

23. Chen $C Y$, Shyu $A B$. AU-rich elements: characterization and importance in mRNA degradation. Trends Biochem Sci 1995; 20: 465-470.

24. Mayeda A, Krainer AR. Regulation of alternative pre-mRNA splicing by hnRNP A1 and splicing factor SF2. Cell 1992; 68: 365-375.

25. Hamilton BJ, Nagy E, Malter JS, Arrick BA, Rigby WF. Association of heterogeneous nuclear ribonucleoprotein $A 1$ and $C$ proteins with reiterated AUUUA sequences. $J$ Biol Chem 1993; 268: 8881-8887

26. Pende A, Contini L, Sallo R, Passalacqua M, Tanveer R, Port JD et al. Characterization of RNA-binding proteins possibly involved in modulating human AT(1) receptor mRNA stability. Cell Biochem Funct 2008; 26: 493-501.

27. Christian K, Lang M, Maurel $P$, Raffalli-Mathieu $F$. Interaction of heterogeneous nuclear ribonucleoprotein A1 with cytochrome P450 2A6 mRNA: implications for post-transcriptional regulation of the CYP2A6 gene. Mol Pharmacol 2004; 65 $1405-1414$.

28. Glisovic T, Ben-David Y, Lang MA, Raffalli-Mathieu F. Interplay between hnRNP A1 and cis-acting element in the $3^{\prime}$ UTR of CYP2A5 mRNA is central for high expression of the gene. FEBS Lett 2003; 535: 147-152.

29. Meisner NC, Hackermuller J, Uhl V, Aszodi A, Jaritz M, Auer M. mRNA openers and closers: modulating AU-rich element-controlled mRNA stability by a molecular switch in mRNA secondary structure. Chembiochem 2004; 5: 1432-1447.

30. Schenkel J, Sekeris CE, Alonso A, Bautz EK. RNA-binding properties of hnRNP proteins. Eur J Biochem 1988; 171: 565-569.

31. Ding J, Hayashi MK, Zhang Y, Manche L, Krainer AR, Xu RM. Crystal structure of the twoRRM domain of hnRNP A1 (UP1) complexed with single-stranded telomeric DNA. Genes Dev 1999; 13: 1102-1115.

32. Burd CG, Dreyfuss G. RNA binding specificity of hnRNP A1: significance of hnRNP A1 high-affinity binding sites in pre-mRNA splicing. EMBO J 1994; 13: 1197-1204.

33. Xu RM, Jokhan L, Cheng X, Mayeda A, Krainer AR. Crystal structure of human UP1, the domain of hnRNP A1 that contains two RNA-recognition motifs. Structure 1997; 5 559-570.

34. Pinol-Roma S, Dreyfuss G. Shuttling of pre-mRNA binding proteins between nucleus and cytoplasm. Nature 1992; 355: 730-732.

35. Guil S, Long JC, Caceres JF. hnRNP A1 relocalization to the stress granules reflects a role in the stress response. Mol Cell Biol 2006; 26: 5744-5758.

36. Tan HT, Zubaidah RM, Tan S, Hooi SC, Chung MC. 2-D DIGE analysis of butyrate-treated HCT-116 cells after Enrichment with heparin affinity chromatography. J Proteome Res 2006; 5: 1098-1106

37. Rehemtulla A, Hamilton CA, Chinnaiyan AM, Dixit VM. Ultraviolet radiation-induced apoptosis is mediated by activation of CD-95 (Fas/APO-1). J Biol Chem 1997; 272 25783-25786.

38. Deng J, Harding HP, Raught B, Gingras AC, Berlanga JJ, Scheuner D et al. Activation of GCN2 in UV-irradiated cells inhibits translation. Curr Biol 2002; 12: 1279-1286.

39. Wu S, Hu Y, Wang J-L, Chatterjee M, Shi Y, Kaufman RJ. Ultraviolet light inhibits translation through activation of the unfolded protein response kinase PERK in the lumen of the endoplasmic reticulum. J Biol Chem 2002; 277: 18077-18083.

40. Van Eden ME, Byrd MP, Sherrill KW, Lloyd RE. Translation of cellular inhibitor of apoptosis protein 1 (c-IAP1) mRNA is IRES mediated and regulated during cell stress. RNA 2004; 10 469-481.

41. Holcik M, Lefebvre CA, Hicks K, Korneluk RG. Cloning and characterization of the rat homologues of the inhibitor of apoptosis protein 1,2, and 3 genes. BMC Genomics 2002; 3 5-10.

\section{Supplementary Information accompanies the paper on Cell Death and Differentiation website (http://www.nature.com/cdd)}

